\title{
Postnatal SARS-CoV-2 Infection and Immunological Reaction: A Prospective Family Cohort Study
}

\author{
Julia Preßler ${ }^{1}$, Sara Fill Malfertheiner ${ }^{1}$, Michael Kabesch ${ }^{1}$, Heike Buntrock-Doepke ${ }^{1}$, \\ Sebastian Häusler ${ }^{1}$, Andreas Ambrosch ${ }^{2}$, and Sven Wellmann ${ }^{1}$ \\ ${ }^{1}$ University of Regensburg \\ ${ }^{2}$ Barmherzige Bruder gemeinnutzige Trager GmbH
}

May 20, 2020

\begin{abstract}
Postnatal SARS-CoV-2 Infection and Immunological Reaction: A Prospective Family Cohort Study
\end{abstract}

To the Editor

The coronavirus disease 2019 (COVID-19) caused by severe acute respiratory syndrome coronavirus 2 (SARSCoV-2) appears milder in children but little is known about neonates and about the chains of infections after delivery. ${ }^{1-3}$ When in early March 2020 a midwife in our large maternity and perinatal center returned from vacation in Ischgl, Austria, she triggered a COVID-19 outbreak affecting 36 midwives, nurses and doctors. We reported previously on the successful containment of this outbreak and characterized the clinical symptoms and immunoglobulin development in staff members exposed to SARS-CoV-2. ${ }^{4-5}$

Here, we present the data of all deliveries with varying degrees of unprotected parental contact with SARS$\mathrm{CoV}$-2-infected personnel during the first, precontainment, week of the outbreak. Of the 66 families concerned, 61 consented to a prospective study (University of Regensburg institutional review board ID 201791-10) involving serial symptom interview, serial SARS-CoV-2 screening in throat rinsing fluid (parents) and feces (infants), and serum IgA and IgG antibody studies (parents and infants) 4-5 weeks postpartum. 18 families had extensive unprotected contact with infected staff lasting $>15$ minutes at $<1.5$ meters distance (Robert Koch Institute [RKI] risk category I). These families had their first SARS-CoV-2 test in the first week after delivery; they were quarantined for [?]2 weeks after discharge home and received weekly study visits. The remaining 43 less exposed families received only two visits.

We tested for SARS-CoV-2 by real-time reverse transcriptase-polymerase chain reaction (RT-PCR) for N2 and E gene, Xpert(C) Xpress SARS-CoV-2, Cepheid, and for serum IgA and IgG antibodies (EUROIMMUN AG, Lübeck, Germany) as previously published. ${ }^{5}$ In addition, to verify the antibody responses we performed a second antibody assay in serum and breast milk, which uses a recombinant protein representing the nucleocapsid antigen for determination of all kind of antibodies against SARS-CoV-2 following the manufacturer's instructions (Elecsys anti-SARS-CoV-2, Roche Diagnostics, Penzberg, Germany). According to the manufacturer's recommendations for both antibody assays from EUROIMMUN and Roche Diagnostics, a cutoff index of $<1.0$ was considered non-reactive (negative for anti-SARS-CoV-2 antibodies) and a value [?] 1.0 reactive (positive).

One or both parents from 16 families reported symptoms suggestive of a SARS-CoV-2 infection within 2 weeks postpartum (Table 1). Three of their infants (all spontaneous births) displayed nonspecific signs of infection similar to late-onset sepsis, including fever, dyspnea and compromised circulation leading to admission to our neonatal intensive care unit, at day of life 5 (ID 3), 10 (ID 7) and 26 (ID 1), resolving within few days (Figure). Blood cultures and tests for non SARS-CoV-2 viruses remained negative. Although 
families with symptoms did not differ in baseline characteristics from those without $(\mathrm{n}=45)$, risk category I families tended to be at higher symptom risk (Table 1).

Five of the 16 families reporting mild COVID-19-compatible symptoms actually contracted COVID-19 based on the RT-PCR and antibody evidence (Figure). Two of the three symptomatic neonates were RT-PCR positive and one asymptomatic neonate. Surprisingly, neither the 3 neonates tested positive for SARS-CoV-2 nor the uninfected newborns had elevated or even borderline antibodies. All antibody results obtained by the EUROIMMUN assay were confirmed by the Roche Diagnostics assay. Of the symptoms prospectively recorded in adults only anosmia appeared COVID-19-specific (Figure). Only one mother (ID 3) produced IgG-positive breast milk. Two neonates, one asymptomatic and one symptomatic (ID 4 and 7, respectively), excreted virus in feces for weeks (Figure).

Differences in neonatal disease onset timing, between day of life 5 and 26, reflect different chains of intrafamily infection. Due to our unique study setting, antepartum infections can be excluded. Albeit we cannot exclude completely the risk of vertical infection via breastmilk, much more likely is postnatal infection through horizontal transmission. While separation of the newborn from the COVID-19 suspected or proven mother would theoretically lower infection risk as e.g. suggested by China consensus guidelines ${ }^{6}$ we kept our practice from before the outbreak supporting skin-to-skin care, rooming-in, and breastfeeding for infants born to mothers with COVID-19 in line with the recommendations from the WHO. ${ }^{7}$ The important hygiene changes from the time before the COVID-19 outbreak and now are the various protection measures around the mother infant dyad, including screening of all pregnant women admitted to the maternity hospital and isolation until SARS-CoV-2 test is negative, surgical face masks for all personnel and patients, proper personal protective equipment when working with patients under investigation for SARS-CoV-2 or for confirmed cases as explained in detail elsewhere. ${ }^{8}$

The outbreak coincided with the seasonal flu peak ultimately responsible for most recorded symptoms. Indeed the coincidence blurred initial pandemic awareness, with some staff and parents already wearing surgical face masks for seasonal flu protection.

Together, like their parents, newborns can contract COVID-19 in the first weeks postpartum and their symptoms may show similarities with late onset sepsis. In adults, anosmia may differentiate mild COVID-19 from common flu.

\section{Literature}

1. Zeng L, Xia S, Yuan W, Yan K, Xiao F, Shao J, Zhou W. Neonatal Early-Onset Infection With SARSCoV-2 in 33 Neonates Born to Mothers With COVID-19 in Wuhan, China. JAMA Pediatr. 2020 Mar 26. doi: 10.1001/jamapediatrics.2020.0878.

2. Zhang ZJ, Yu XJ, Fu T, Liu Y, Jiang Y, Yang BX, Bi Y. Novel Coronavirus Infection in Newborn Babies Under 28 Days in China. Eur Respir J. 2020 Apr 8. pii: 2000697. doi: 10.1183/13993003.00697-2020.

3. Wang S, Guo L, Chen L, Liu W, Cao Y, Zhang J, Feng L. A case report of neonatal COVID-19 infection in China. Clin Infect Dis. 2020 Mar 12. pii: ciaa225. doi: 10.1093/cid/ciaa225.

4. Kabesch M, Roth S, Brandstetter S, Hausler S, Juraschko E, Weigl M, Wellmann S, Lang T, Schmidt B, Salzberger B, Ambrosch A. Successful containment of COVID-19 outbreak in a large maternity and perinatal center while continuing clinical service. Pediatr Allergy Immunol. 2020 Apr 22. doi: 10.1111/pai.13265.

5. Brandstetter S, Roth S, Harner S, Buntrock-Dopke H, Toncheva A, Borchers N, Gruber R, Ambrosch A, Kabesch M. Symptoms and immunoglobulin development in hospital staff exposed to a SARS-CoV-2 outbreak. Pediatr Allergy Immunol. 2020 May 15. doi: 10.1111/pai.13278.

6. 1: Wang L, Shi Y, Xiao T, Fu J, Feng X, Mu D, Feng Q, Hei M, Hu X, Li Z, Lu G, Tang Z, Wang Y, Wang C, Xia S, Xu J, Yang Y, Yang J, Zeng M, Zheng J, Zhou W, Zhou X, Zhou X, Du L, Lee SK, Zhou W; Working Committee on Perinatal and Neonatal Management for the Prevention and Control of the 2019 Novel Coronavirus Infection. Chinese expert consensus on the perinatal and neonatal management for the prevention and control of the 2019 novel coronavirus infection (First edition). 
Ann Transl Med. 2020 Feb;8(3):47. doi: 10.21037/atm.2020.02.20. Review.

7. World Health Organizations. Clinical management of severe acute respiratory infection when COVID19 disease is suspected. Available at: https://www.who.int/publications-detail/clinical-managementof-severe-acute-respiratory-infection-when-novel-coronavirus-(ncov)-infection-is-suspected . Accessed May 15, 2020

8. Chandrasekharan P, Vento M, Trevisanuto D, Partridge E, Underwood MA, Wiedeman J, Katheria A, Lakshminrusimha S. Neonatal Resuscitation and Postresuscitation Care of Infants Born to Mothers with Suspected or Confirmed SARS-CoV-2 Infection. Am J Perinatol. 2020 Apr 8. doi: 10.1055/s0040-1709688.

\section{Figure legend}

Fourteen families (ID 1-14) reporting COVID-19-compatible symptoms within 2 weeks postpartum, listed by birth order between March 9 and 15, 2020, and screened twice (two further symptomatic families were unavailable for the second screening). Families in Robert Koch Institute risk category I exposed to prolonged and close unprotected contact $(>15$ minutes at $<1.5$ meters distance) with infected staff were screened for SARS-CoV-2 by RT-PCR 1 week and 4-5 weeks postpartum. All other families were screened once only, at 4-5 weeks. Circle, mother; triangle, infant; rectangle, father; red, positive; green, negative; clear, not done; brackets, not applicable; wks, weeks; RT-PCR, reverse transcriptase-polymerase chain reaction.

Julia Pressler, MD (1); Sara Fill Malfertheiner, MD (2); Michael Kabesch, MD (3); Heike Buntrock-Dopke (3); Sebastian Hausler, MD (2); Andreas Ambrosch, MD (4); Sven Wellmann, MD (1)

1. Department of Neonatology, University Children's Hospital Regensburg (KUNO), Campus St. Hedwig

2. Department of Obstetrics and Gynecology, University Hospital Regensburg, Campus St. Hedwig

3. Department of Paediatric Pneumology and Allergy, University Children's Hospital Regensburg (KUNO), Campus St. Hedwig

4. Institute of Laboratory Medicine, Microbiology and Hygiene

Hospital of the Order of St. John, University of Regensburg, Regensburg, Germany

\section{Corresponding author:}

Prof. Dr. Sven Wellmann

University Children's Hospital Regensburg (KUNO)

Hospital St. Hedwig of the Order of St. John

Steinmetzstr. 1-3

D-93049 Regensburg, Germany

Phone: +49-941-369-5401

Fax: +49-941-369-5802

E-mail: sven.wellmann@ukr.de

\section{Hosted file}

Table Families 18052020.docx available at https://authorea.com/users/324630/articles/452755postnatal-sars-cov-2-infection-and-immunological-reaction-a-prospective-family-cohortstudy 


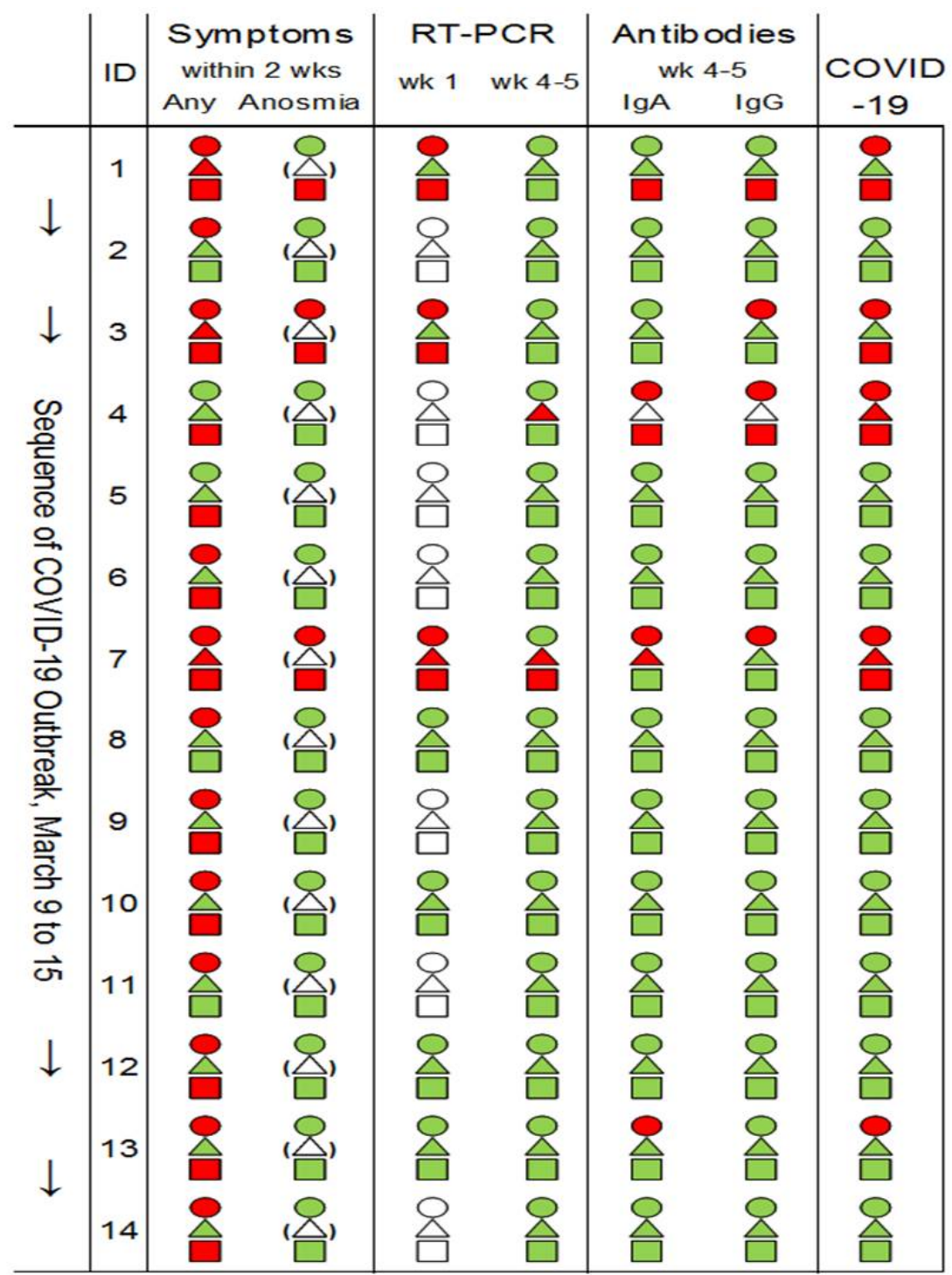

